is concerned; as in this manner the singularly abnormal atmospheric conditions to which they are exposed may be most conveniently studied.

The houses to which I refer are known in the highlands as "bothies," and are the homes of the hardy crofters, to whose grievances public attention has of late been strongly directed. Many of them live under the same roof as their cattle, and in numerous instances the air of the dwelling reeks with the impure exhalations given off from the excretions of these joint inmates of the cabin. The primitive dwellings are warmed by a peat-fire kept constantly burning in the centre of the floor. The luxury of a chimney is often altogether unknown. The smoke which rises from the combustion of this fuel, atter thoroughly diffusing itself through every nook and corner of the building, makes its escape by a hole in a corner of the roof. Now it may be asked, how is the health of these persons influenced by inhaling constantly, both by day and by night, such an atmosphere as this; an atmosphere so pungent, that considerable irritation of the eyes and nostrils is frequently experienced by those exposed to the fumes?

Generally speaking, these highlanders are remarkably vigorous and long lived, and singularly exempt from the ravages of tubercular phthisis. Indeed, so rare is consumption in these hovels, that I was led to investigate the causes of this immunity, upwards of twenty-five years ago, and published the results of my inquiries in an article on the Non-prevalence of Consumption in the Hebrides. and along the North-Western Coast of Scotland, which appeared in the British and Foreign Medico-Chirurgical Review for October, 1860. At that time, I visited most of the districts to which my investigations extended; and from what I saw and heard, I came to the conclusion that the comparative immunity from phthisis which these persons enjoy, is to be ascribed chiefly, at all events, to the inhalation of the peat smoke, and the antiseptic ingredients contained therein, the tar, the creasote, and the tannin, together with various volatile oils and resins, black unctuous peat being rich in these substances. At that time, I need hardly say, nothing was known of the bacillus of Koch. It further appeared that any exemption from attacks of consumption which these highlanders enjoyed was only extended to them so long as they resided in their smoky huts. When they migrated to other parts of the country, or took up their abode in chimnied dwellings, they often suffered like their neighbours; nor, after the lungs once became infected, was a return to the homes of their fathers followed by favourable results. The fumes of the smoky cabin then exercised no curative influence.

The inference to be drawn from these remarks is sufficiently obvious. When the bacillus has once established itself in the lungs, the time for antiseptic remedies has gone by. On the other hand, where there is merely a predisposition to phthisis, whether hereditary or acquired, where also the climatic or social conditions for its diffusion are favourable, and where healthy persons are brought into close contact with those who are suffering from the disease, there it is reasonable to assume that disinfectants may prove of great value as prophylactics. Hence we may anticipate that, in the course of time, an efficient system of aerial fumigation will not alone assist the physician in warding off dis. ease, but may enable the surgeon also to dispense with the cumbrous appliances associated with antiseptic dressings and the steam-diffusing urn.

\section{NOTES ON A CASE OF COLOTOMY.}

Read before the Essex District of the East Anglian Branch.

By THOMAS SIMPSON, M.R.C.S.Eng., Coggeshall, Essex.

George P. came under my care in November, 1880, complaining of constipation that had been increasingly troublesome. The exact date on which the bowels ceased to act I cannot remember; but, after he had attended at the surgery several times, I began to attend him at his home on November $27 \mathrm{th}, 1880$. He was a well developed, strong, healthy man, 71 years old, a wheelwright, and was a sober, steady, industrious workman. $\mathrm{He}$ had an inguinal hernia on the right side, which could easily be reduced, and which was entirely omental. The symptoms became intensified. He underwent the usual practice pur. sued in such cases, chief reliance being placed on the internal ad. ministration of belladonna and the free use of injections. The long tube of the stomach-pump was used for the latter purpose; and on one occasion, after paying out the tube more freely than I had been able to do before, I found that it had turned in the bowel, so that the perforated end of the tube presented itself at the anus. The difficulty seemed to be at the sigmoid flexure of the colon and the obstruction was such that neither motion nor flatus passed. No food could be retained; any attempt to take it only caused vomiting. The abdomen became greatly distended; and, as the man was lean, the course of the colon could easily be traced - a matter which rendered the subsequent operation easier to accomplish. So the case continued, the man becoming weaker and weaker, and his condition more hopeless, as every effort made for his relief turned out to be vain and futile. On Sunday, December 12th, I persuaded him to let me perform colotomy. With the help of Mr. Galpin of Kelvedon, and my assistant, Mr. W. E. Woodman (now practising at Croydon), l performed the operation in the usual situation. I succeeded in bringing the colon well forward, and in getting it safely secured to the external wound before opening it. When I opened it, enormous quantities of liquid fæculent matter spouted out. I passed my finger down the gut as far as I could, but could find no obstruction.

The after-treatment was very simnle. He kept his bed for about three weeks, and the wound was dressed with spongio-piline. Onc motion passed naturally, and then all that passed from the bowel. came through the artificial opening. He recovered quickly, and, in: about two months, was at viork again. I tried to close the external opening with an ivory ball, that might be removed so as to allow the fæces to escape ; but, after trying several expedients of this kind, and for this purpose, I found that square pieces of spongio-piline, kept closely applied by means of a broad bandage, were the most efficient.

The man often worked for me after the operation, and never com plained of any inconvenience, and he continued in active work till January 15 th, 1885. He had taken cold a few days before this date, and, on the evening of that day, when coughing, he felt something give way, and found that a large swelling had appeared just below the artificial anus. A great deal of blood oozed from the swolling, and he suffered greatly from pain.

On examining him, I found him very weak and almost pulseless, and could not on that account persevere long in trying to reduce the swelling. He died exhausted on January 17 th.

We opened the body on January 19th, and found that the hernia on the right side was omental, the omentum being attached by old adhesions to the anterior surface of the descending colon. The colon was distended, as were the smaller intestines. In the preparation now exhibited, a large loop of the ileum can be seen that had been forced through the abdominal walls below the artificial anus, and hat there become strangulated; parts of this intestine were becoming gangrenous. The colon below the seat of operation was empty, savo two extremely hard lumps of scybalous matter. 'I'here was nothin besides these to account for the symptoms to obviate which the opera. tion was performed.

REMARKS. - The case is interesting on two grounds ; first, as show ing that the operation may be attempted on old people with a fair prospect of prolonging their lives, as in this instance, for over four years ; and, secondly, on account of its peculiar, and, so far as I know. unique termination

The preparation illustrating this case has been sent to the museun of St. Bartholomew's Hospital.

\section{NITRITE OF AMYL AN ELIMINATOR OF URIC ACID ; ITS EMPLOYMENT IN THE TREATMENT OF GOUT.}

By ARCHIBALD D. MACDONALD, M.D., Liverpool.

I Propuse to support the title of this short paper by three distinct, yet closely connected statements.

1. On September 13 th, 1882, I attended a case of what is usuall called puerperal eclampsia. After the first hour, and during thre: and a half hours, I repeatedly gave nitrite of amyl by inhalation, in the usual way and dose. In the course of the following eighteen hours one minim of nitro-glycerine, of 1 per cent. solution, was four times administered, and chloroform to a limited extent, as well as an operative procedure, also marked that period. Nine hours after the last dose of nitro-glycerine ; that is, about $31 \frac{1}{2}$ hours after the first inhalation of nitrite of amyl, I drew off the urine. After standing for nearly 48 hours, it was seen to have deposited, inter alia, crystal, of uric acid.

Then, this fact somewhat puzzled me, but I was inclined, for reason; which need not be specified, deduced from the hypotheses of authorities on the subject of this eclampsia, to look upon this as an interesting clue to a rationale of the colchicum treatment of the disease. A notice of the observations of Signori Guiseppe and Sansoni, of Turill, however, has forced me to reconsider the point. 
2. Accordingly, I instituted a check-experiment, the subject of which was a healthy adult, whose urine was previously normal. The experiment, except the non-adininistration of chloroform, corresponded, as far as possible, with the case just mentioned. Thus, from 10.45 A.M. till 2.50 P.M., seven inhalations of 5 minims each of nitrite of amyl were taken. The urine passed at 4 o'clock, an hour after food, was of a rlear dark straw-colour, very acid in reaction, and, on cooling, deposited a little mucus, and copious urates. One ounce withont the urates, hut plus a drachm of hydrochloric acid, showed, after forty-eight hours had elapsed, a large deposit of uric aciu crystals. Also, as in the ease, nitro-glycerine was taken.

A similar quantity, passed seven hours after the last, almost free from visible urates, similarly treated, gave what may be relatively termed a very considerable deposit; and next day (36 hours after the first drug was first administered), from the sample, a considerable amount of the crystals was obtained.

I hope shortly to narrate an experiment with regard to the effect of nitro-glycerine per se.

Thus I was able to confirm the statement of the Italian observers named, and also to find that the balance of fact against theory compels me now to believe that the excretion of uric acid in the case of eclampsia was, at all events, largely due to the drug employed, and not wholly to the disease, and that no deduction could be drawn from the premisses as to any connection between the gouty diathesis and puerperal celampsia, or the consequent colchicum-treatment of that affection. My inquiry into the symptom had no pretence to have been exhaustive ; the case, however, is pretty clearly, though not yet quite logically, proven now.

3. A practical application of this property of the nitrite of amyl as an eliminator of the gout-poison immediately occurred to me, to which I at once gave effect.

H. G., of Tue Brook, a powerful, slightly ruddy man, aged 37, had suffered from gout, and now had an attack chiefly in the ankle-joint. For fourdays, he had had an alkaline mixture with colchicum, and hac obtained some relief, also, from local treatment. At 4 P.M. on April 17 th, his urine was elear straw-colomred; on standing; it contained a very little mucus, no other (leposit. One ounce, acldulated with a drachm of hydrochloric acid as before, and set aside for forty-eight hours, showed only a very few erystals of uric acid.

That statement enables a fair judgment to be formed of the state of matters previously to the use of the nitrite, during which the medicine and special local treatment were, of course, abandoned.

The first inhaled dose of four minims was given by myself at 4.2 ; a faint flush and sensation of fulness in the head resulted. At 6, 8, and 10 o'clock, the dose was repeated. Next morning, at 9, he was much better, but had a slight headache, which soon passed off. His urine passed at that hour showed a very acid reaction, and, being treated as above, gave what $I$ describe, in the absence of a quantitative analysis, as a considerable deposit of uric acid. On the 20th, be was able to walk, the ankle-joint being very nearly well.

Remarks would be redundant. Further research is manifestly required. I will only say that all I claim is to have established a prima ficcie case for the administration of nitrite of amyl as a rational therapeutic agent in those cases of gout, in which the usual contraindications do not prevent its use. And if we can by its means procure a more than normal discharge of uric acid when an attack threatens, we may find it prophylactic as well as curative.

\section{SURGICAL MEMORANDA.}

\section{LIGATURE OF 'THE FIRST PART OF THE AXILLARY ARTERY, FIRST PART OF SUBCLAVIAN AND INNOMINATE ARTERIES.}

THE plan usually recommended for this operation is to make a trans. verse incision, and to divide the fibres of the pectoralis major through. out the whole extent of the wound.

Some years ago, I practised ligaturing the vessel by means of an oblique incision over the line of apposition of the deltoid and pectoralis major, simply separating the two muscles from each other, and holding them apart with retractors. The operation is quite feasible in this minner, with a sufficient incision through the superficial coverings, and relaxation of the muscles by position. To obtain more light, and render the procedure easier, the oblique incision may be shortened, and a transverse incision added, dividing the skin and fascia at the lower border of the clavicle, and separating the fibres of the clavicular head of the pectoralis major from their attachment to the bone. The triangular flap of skin and fascia and the head of the muscle can then be turned down without interfering with the nerve supply. By using the handle of the scalpef the edge of the pectoralis minor may be defined, and the artery may subsequently be cleared and tied in any part of the space between the subclavius muscle and the lesser pectoral muscle. The cephalic vein is looked for. early, and held aside with a blunt hook. I have not had the opportunity of performing this operation on the living body.

About two years ago, a case of a large aneurysm of the subclavian in a female came under my care, and I had decided to try distal ligature of the first part of the axillary in this way, but the patient would not consent to an operation. I had hoped that ligature of the axillary might suffice to cure the aneurysm, without having to resort to any interference, either with the first part of the subclavian or with the innominate. I say iuterference ; because, if ligature of the axillary had failed, I should have tried lifting the subclavian or innominate with an aneurysm-needle sufficiently to arrest pulsation, retaining the needle in position for a few hours to enable the blood to coagulate in the sac, then withdrawing the needle, and closing the wound altogether.

It appears to me that it is inexpedient to go on repeating opera. tions so fatal as ligature of the first part of the subclavian or innominate, and that some plan of temporary occlusion, either by ligature quite lightly tied, and afterwards removed, or with finger or aneurysm-needle, offers a fair prospect of success.

The mode of ligature of the axillary artery here described will, I think, be found superior to the ordinary method.

Walter Rivington, F.R.C.S.Eng., etc.

\section{CLINICAL MEMORANDA.}

\section{THE COMMUNICABILITY OF CONSUMPTION}

I PUT this case forward as a possible instance of contagion in phthisis. A woman is now under my care at the Royal Hospital for Children and Women, with the signs of a cavity at the right apex and con. solidation at the left apex. There is no tubercular taint in her family, and she was quite healthy until her present illness. Her husband died of phthisis fifteen months ago. For five months before his death, she was in constant attendance on him, slept in the same bed with him, and only left the room on rare occasions. Two months after she began to nurse him, she commenced to cough, and her illness has continued ever since. Dr. Waugh, the resident medical officer at the Brompton Hospital for Consumption, informs me that the husband was under treatment there for advanced phthisis. In his ease, too, as in his wife's, there was no family-history of phthisis.

\section{W. B. HADDEN, 21; Welbeck Street, W.}

\section{ALOPECIA AREATA, PARASITIC SYCOSIS, AND RINGWORM} OF THE BODY IN THE SAME INDIVIDUAL.

A. P. consulted me at St. John's Hospital, on April 2nd, for the fol. lowing condition. He had unsymmetrical and absolutely bald patches on his sealp. Ho had typical ringworm of his : neck and back of right hand. One-half of the circumference of the ringworm on the neck extended into the hair-roots, but the hairs were not broken off, as.wo see on the scalps of young children with the same malady. The following axioms spring from this short narrative. 1 . We have a common cause for the three diseases. 2. Adults do not develop on the scalp the condition which is known as tinea tonsurans. 3. Alopecia areata is the prototype of tinea tonsurans.

Tom Robinson, M.D., 9, Prince's Street, Cavendish Square, W.

\section{VARICOSITY OF THE LINGUAL VEIN AS A DIAGNOSTIC} SIGN.

WHILsT, on the one hand, I am most unwilling to decry the credit due to Messrs. Dickson and Whitehouse for their acumen in connection with this subject, on the other, I cannot but confess that to me it seems that works on diagnosis are quite correct in omitting special reference to the lingual veins as indicating important vascular changes in the state of the cerebral vessels; for the state of these can with much more accuracy be presumed from the general arterial condition. We all know how frequently atheroma occurs in advanced life; and, although it. is a trite observation, that the obstruction to the flow of blood through the arteries, which atheromatous disease induces, leads to varicose veins, so that, when atheroma is present to any extent, we may confidently expect some degree of varix, the converse does not hold ; varix does not necessarily imply atheroma. Varix obviously is first observed clinically in the superficial veins, and especially in those 